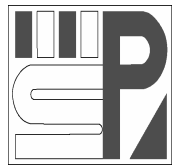

Science Press
Journal of Arid Land

2012, 4(3): 281-291

doi: 10.3724/SP.J.1227.2012.00281

jal.xjegi.com; www.chinasciencejournal.com

\title{
Physiological responses of Populus euphratica Oliv. to groundwater table variations in the lower reaches of Heihe River, Northwest China
}

\author{
Yang ZHAO ${ }^{1}$, ChuanYan ZHAO ${ }^{1 *}$, ZhongLin XU ${ }^{2}$, YiYue LIU $^{1}$, Yao WANG ${ }^{1}$, Chao WANG ${ }^{3}$, \\ HuanHua PENG ${ }^{3}$, XiangLin ZHENG ${ }^{1}$ \\ ${ }^{1}$ State Key Laboratory of Pastoral Agricultural Ecosystem, Institute of Arid Agroecology, School of Life Science, Lanzhou Uni- \\ versity, Lanzhou 730000, China; \\ ${ }^{2}$ MOE Key Laboratory of Oasis Ecology, College of Resource and Environmental Science, Xinjiang University, Urumqi 830002, \\ China; \\ ${ }^{3}$ Key Laboratory of Western China's Environment Systems MOE, Lanzhou University, Lanzhou 730000, China
}

\begin{abstract}
Riparian vegetation in the lower reaches of Heihe River serves important ecological functions. However, the riparian ecosystems have been constantly deteriorating in the past 30 years simply due to water interception for oasis agricultural irrigation in the middle reaches of the river. This study pays a particular attention to Populus euphratica Oliv. forest because it is a dominant component of the riparian ecosystem in the lower reaches of Heihe River where the depth of groundwater table is the controlling factor in sustaining riparian ecosystems. To reveal leaf-related physiological responses of Populus euphratica Oliv. forest to groundwater table variations, we analyzed the relationships between the depth of groundwater table (DG) and three leaf-related parameters, i.e. leaf stomatal density (SD), specific leaf area (SLA), and stable carbon isotopic composition $\left(\delta^{13} \mathrm{C}\right)$. Our results show that the relationship between DG and leaf SD is a bi-mode one shaped by both salt stress and water stress. That is, salt stress appeared in shallow groundwater conditions and water stress happened in deep groundwater conditions, and the thin layer around $2.7 \mathrm{~m}$ of DG is a stress-free layer. Leaf SD fluctuated according to the DG variation, first decreased with increasing DG, then increased at depths ranging 2.7-3.7 m, and after a relatively stable plateau of SD at depths ranging 3.7-5.2 m, decreased again with increasing DG. Our results also show that SLA decreased exponentially with increasing $D G$ and foliar $\delta^{13} \mathrm{C}$ values are also strongly dependent on $\mathrm{DG}$, further demonstrating that these two parameters are sensitive indicators of water stress. The exponential curve suggests that SLA is more sensitive to DG when groundwater table is shallow and $3 \mathrm{~m}$ seems to be a threshold beyond which SLA becomes less sensitive to DG. Foliar $\delta^{13} \mathrm{C}$ becomes more sensitive when the groundwater table is deep and $7 \mathrm{~m}$ seems to be a threshold below which the $\delta^{13} \mathrm{C}$ signature becomes more sensitive to DG. These findings should be helpful in monitoring the growth and development of Populus euphratica Oliv. forests and also in providing protection measures (i.e. DG related) for Heihe River riparian forests.
\end{abstract}

Keywords: Populus euphratica Oliv.; stable carbon isotopic composition; stomatal density; specific leaf area; groundwater table

Riparian vegetation builds narrow strips of ecological refugees along rivers in arid areas and serves various ecological functions (Naiman and Décamps, 1997) which include maintaining water quality, sustaining biodiversity, and even preserving landscape aesthetics (Nilsson et al., 1997; Sidle, 2004). The ecological importance of the riparian ecosystems in the low reaches of Heihe River has long been ignored simply due to the fact that water use for oasis agricultural irrigation has been the highest priority (Ji et al., 2006). However, the signs of ecological crisis resulted from overuse of water for oasis agricultural irrigation in the

Received 2011-10-16; accepted 2012-04-18

*Corresponding author: ChuanYan ZHAO (E-mail: nanzhr@lab.ac.cn) 
middle reaches of Heihe River (e.g. the decline of groundwater table, associated disappearance of riparian vegetation, and consequential desertification) has recently motivated a new governmental initiative to restore the deteriorated ecology along the rivers. Heihe River, one of the three large inland rivers in the Hexi Corridor, is a typical example of aforementioned deteriorating riparian ecosystems. This research pays a particular attention to Populus euphratica Oliv. forest because it is a dominant component of the riparian ecosystem in the lower reaches of Heihe River (Ma et al., 1997). It is well documented that the covering area of Populus euphratica Oliv. forest has shrunk from $2.94 \times 10^{4} \mathrm{hm}^{2}$ to $2.06 \times 10^{4} \mathrm{hm}^{2}$ in the past 30 years primarily due to continuous decline of the groundwater table caused by water interception for agricultural irrigation in the middle reaches (Zhang and Shi, 2002). To reveal the physiological responses of Populus euphratica Oliv. forest to groundwater table variations, this study focused on leaf-related physiological characteristics (including stomatal density, specific leaf area, and stable carbon isotopic composition) of Populus euphratica Oliv. trees growing under different groundwater tables. It is expected that the adaptation mechanism of Populus euphratica Oliv. forest to drought can be better understood and that constructive protection measures for the species can be thus promoted.

Many studies have shown that drought stress can imprint traceable physiological traits on plants (Royer, 2001; Liu et al., 2006; Säumel et al., 2010) and the aforementioned three leaf-related parameters (i.e. stomatal density, specific leaf area, and stable carbon isotopic composition) were reported to be such traceable physiological traits particularly for Populus euphratica Oliv. trees (Liu et al., 2006; Li et al., 2010). It should be stressed that leaf, as the photosynthetic and respiration organ of plants, is the most sensitive sensor to the environmental factors (Klich, 2000) and thus leaf-related physiological parameters or indicators should have left traceable traits (Farquhar $e t$ al., 1989; Royer, 2001; Liu and Stüzel, 2004).

Leaf stomatal density (SD) is indicative of physiological response to environmental factors because stoma is a gateway for plants to exchange water and $\mathrm{CO}_{2}$ with the atmosphere. In other words, the leaf stomatal density (SD) controls the efficiency of the exchanges (Tichá, 1982; Ceulemans et al., 1995; Elias, 1995). Leaf SD is reported to be a reasonable indicator of soil moisture condition or water accessibility for natural ecosystems or crops (Yang and Wang, 2001; Wang et al., 2007; Yang et al., 2007), although contradicting results were also reported (Xu and Zhou, 2008; Yadollahi et al., 2011). Specific leaf area (SLA) is the ratio of fresh leaf area to dry weight (Kitajima and Poorter, 2010) and is also reported to be sensitive to soil moisture conditions or water accessibility (Retuerto and Woodward, 1993; Tardieu et al., 1999; Nautiyal et al., 2002; Anyia and Herzog, 2004). Although stable carbon isotopic composition (i.e. $\delta^{13} \mathrm{C}$ ) is generally controlled by photosynthetic pathways, the composition is strongly affected by many environmental factors (Farquhar et al., 1989; Liu et al., 2004), soil moisture or water accessibility being the predominant one (Chen et al., 2002; Ma et al., 2007). Many studies have shown that foliar $\delta^{13} \mathrm{C}$ values are negatively correlated with precipitation, and the negative correlation is more distinctive in arid areas than in moist areas (Farquhar et al., 1989; Williams and Ehleringer, 1996; Zheng and Shangguan, 2007).

\section{Materials and methods}

\subsection{Study area}

Our study area, the lower reaches of Heihe River $\left(41^{\circ} 48^{\prime}-42^{\circ} 42^{\prime} \mathrm{N}, 100^{\circ} 10^{\prime}-101^{\circ} 30^{\prime} \mathrm{E}\right)$ (Fig. 1), is located in a hyper-arid desert in Northwest China where the mean annual precipitation is only $41 \mathrm{~mm}$ and the mean annual evaporation is as high as $3,700 \mathrm{~mm}$. The mean monthly temperature is $26.3^{\circ} \mathrm{C}$ in July and is $-12^{\circ} \mathrm{C}$ in January. It is obvious that the precipitation is ecologically insignificant and the groundwater is the only water source for plants. Our field observations show that the population density (PD) of Populus euphratica Oliv. trees is highly dependent on the depth of groundwater table (DG) (Fig. 2). Specifically, the population density is rather high where the groundwater table is less than $3 \mathrm{~m}$ (Fig. 2); the density is much reduced where the groundwater table is between 3 and $5 \mathrm{~m}$ (Fig. 2b); and the density is very low when the groundwater table is beyond $5 \mathrm{~m}$ (Fig. $2 \mathrm{c}$ ). 


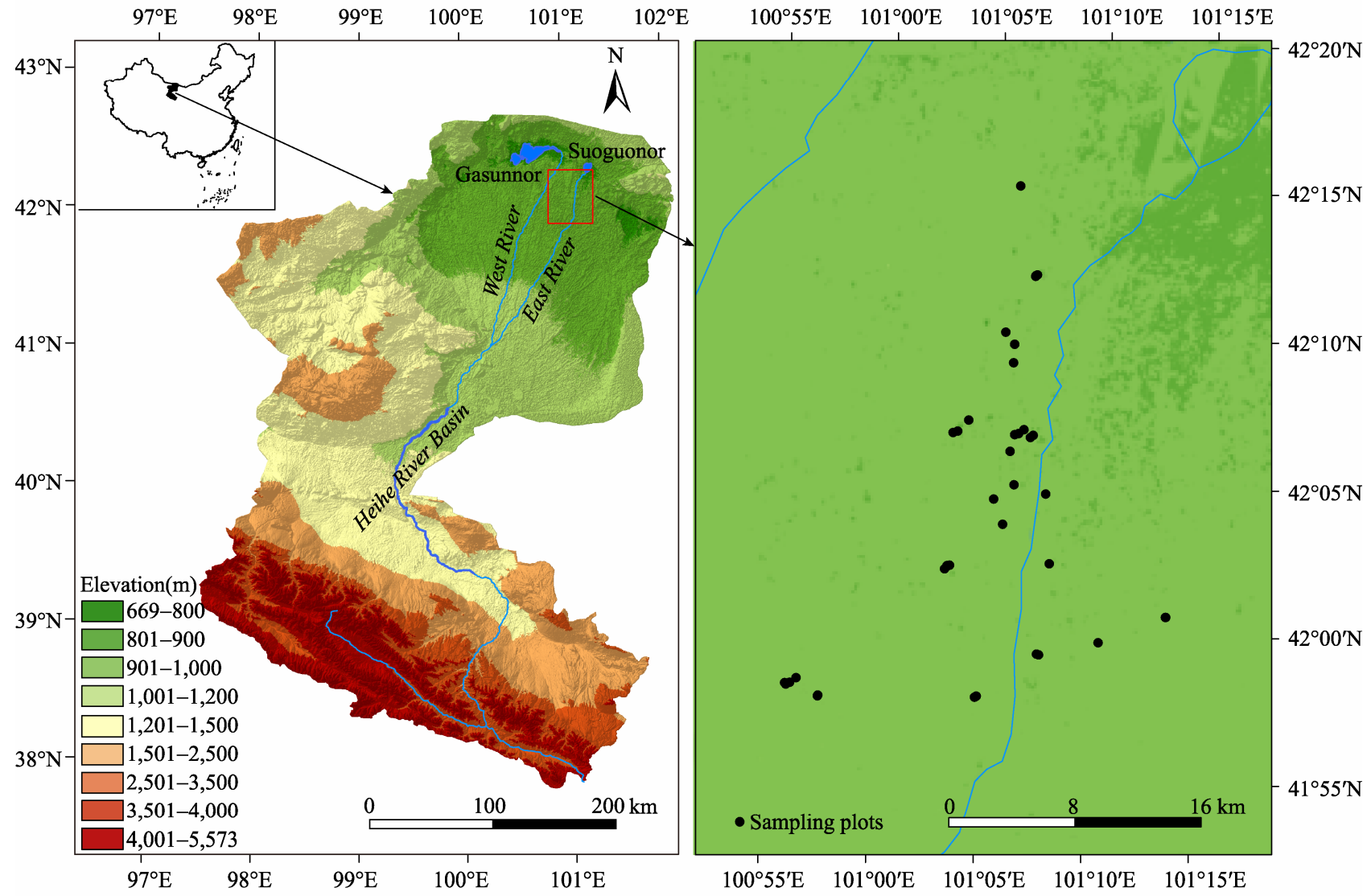

Fig. 1 Location of the study area and distribution of sampling points in the lower reaches of Heihe River
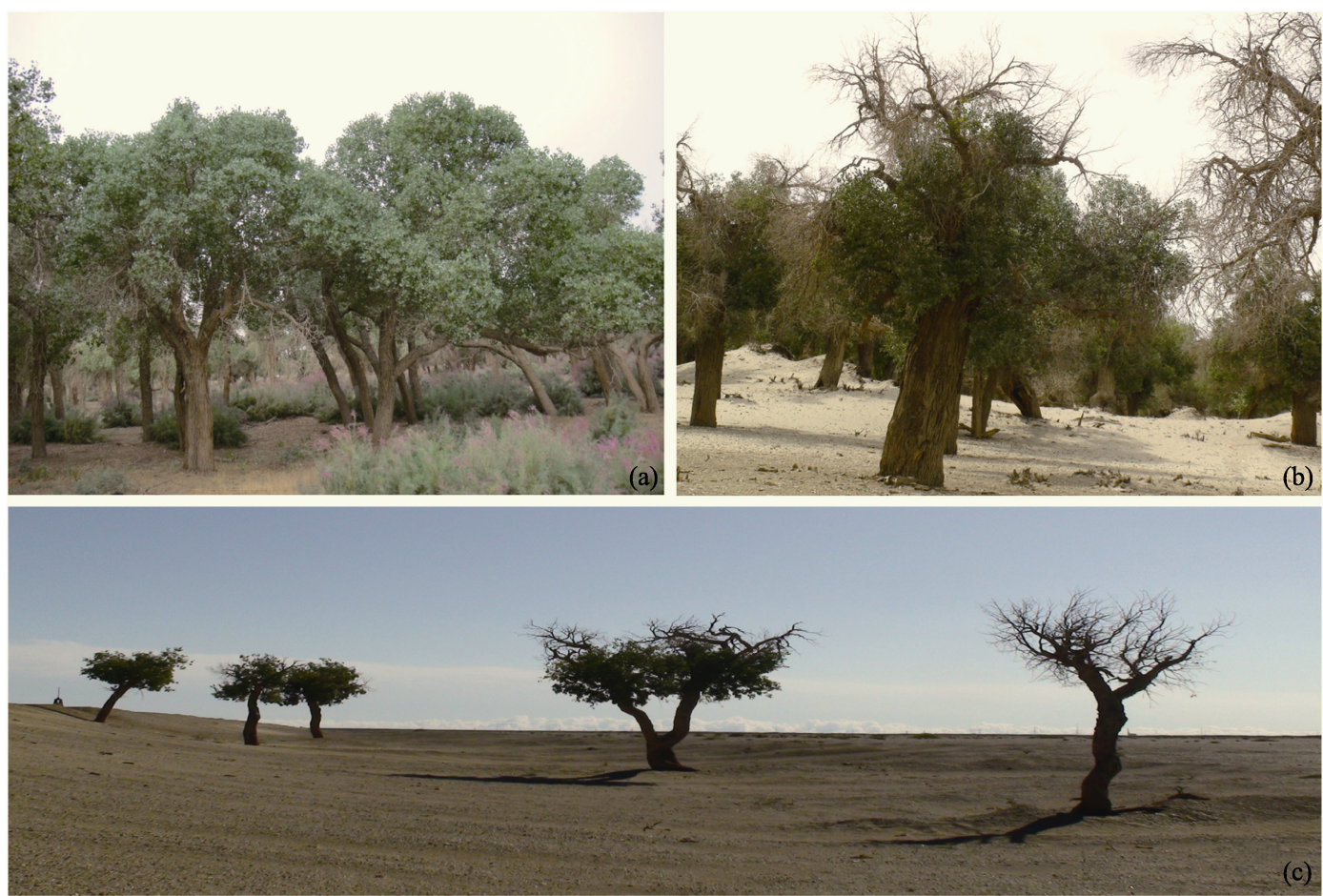

Fig. 2 The population density (PD) of Populus euphratica Oliv. trees with different depths of groundwater table (DG). a, PD is rather high where DG is less than $3 \mathrm{~m} ; \mathrm{b}, \mathrm{PD}$ is much reduced where $\mathrm{DG}$ is between 3 and $5 \mathrm{~m}$; , the density is very low when the groundwater table is beyond $5 \mathrm{~m}$. 


\subsection{Field sampling}

In August 2010, 42 plots of Populus euphratica Oliv., $40 \mathrm{~m}$ in radius, were selected according to the different groundwater tables along the East River (Fig. 1). We located the center of each plot with hand-held GPS. In each plot, the distance of each tree from the center was measured using a laser altimeter and the azimuth angle of each tree was recorded by a compass. The height $(\mathrm{H})$, diameter at breast (DBH), and ratio of died branches to full branches (RBF) of these sample trees were measured. Population density (PD) of Populus euphratica Oliv. was obtained in each plot after investigation. Additionally, the depths of groundwater table (DG) were measured by observation wells in or near each plot at monthly interval in 2009 and 2010. The leaves of Populus euphratica Oliv. were collected. About 30 to 40 pieces of healthy leaves were picked from the four directions (east, south, west and north) in the upper, middle and bottom parts of trees' canopy within each plot.

\subsection{Measurement of stomatal density}

Field-collected and well-preserved fresh leaves were gently washed first and then dried at room temperature. Each of the dried leaves was painted with clear nail varnish in the upper, middle and bottom parts to form imprint of the leaf (Fig. 3a). The imprinted varnish was allowed to dry for 20-30 min and then gently peeled off with adhesive cellophane tape. The epider- mal imprint was placed on a microscopic slide and covered with a cover slip. All of prepared epidermal imprints were examined with a microscope (DM6000, Leica, Germany) at a magnification of 100 and also photographed (Fig. 3b). Five microscopic fields of each slide were randomly selected with each field having a size of $661 \mu \mathrm{m} \times 881 \mu \mathrm{m}$. Stomatal number was obtained using an image processing program. The image processing involves three steps: 1) to classify stomatal photos using object-oriented classification method in eCognition software (Fig. 4a); 2) to input the classified images into ArcGIS to calculate the total number of stomatal pixels and also the total area of stoma in a microscopic filed (Fig. 4b); 3) to calculate SD by dividing the area of a microscopic field with the counted number of stomata.

\subsection{Measurement of specific leaf area}

About 10-20 leaves were randomly selected from each sampling plot and the leaf area of each randomly selected leaf was measured with a KP-90N scanner (KP-90N, Koizumi, Japan). The scanned leaves were dried at $75^{\circ} \mathrm{C}$ in an oven for $48 \mathrm{~h}$ and then weighted. The SLA was calculated as follows:

$$
S L A=\frac{\sum_{i=1}^{n} S_{i}}{W} .
$$

Where, $W$ is the weight of dry leaves collected from each one of the sampling plots and $S_{i}$ refers to the area of a single leaf.
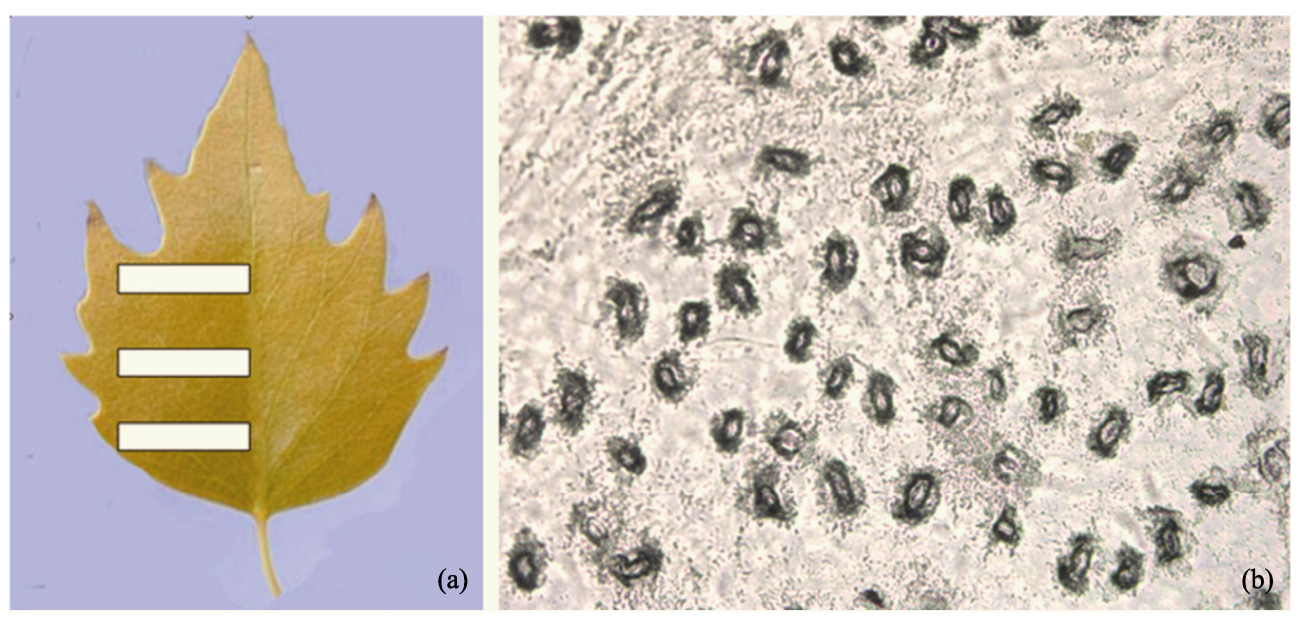

Fig. 3 Materials for the measurement of stomatal density. a, leaf sample of Populus euphratica Oliv. tree (three epidermal imprints were obtained from the three white boxed areas); b, photograph of stomata (oval shaped dark spots) taken by Leica DM6000 Microscope. 

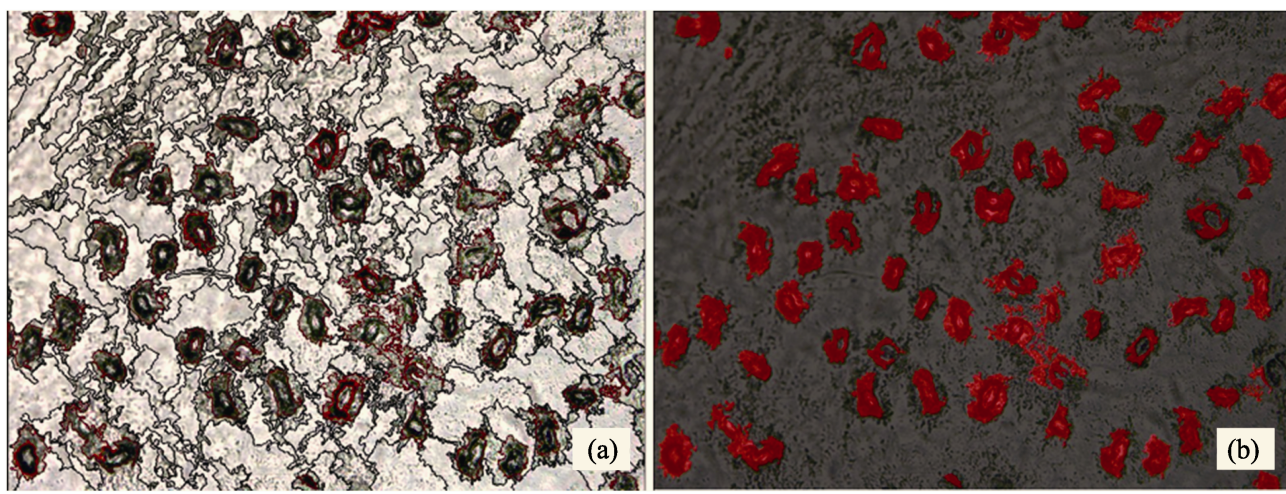

Fig. 4 Image processing for the measurement of stomatal density. a, result of image classification using eCognition software; b, stomatal counting by ArcGIS (the red spots are stomatal grids).

\subsection{Measurement of stable carbon isotopic com- position $\left(\delta^{13} \mathbf{C}\right)$}

Field-collected leaf samples from each one of the sampling plots were gently washed using deionized water and dried at $80^{\circ} \mathrm{C}$ in an oven for $48 \mathrm{~h}$. The dried samples were ground into powder with a mortar and pestle to form a powder sample and then $7 \mathrm{mg}$ of the powder sample was burned in excess of $\mathrm{O}_{2}$. The carbon isotopic composition was determined with Delta Plus mass spectrometer (EA-DELTA ${ }^{\text {plus }}$, Finnigan, American). The $\delta^{13} \mathrm{C}$ value for each sample was calculated using the following equation:

$$
\delta^{13} C=\left(R_{\text {sample }} / R_{\text {standard }}-1\right) \times 1000 .
$$

Where, $R_{\text {sample }}$ is the ratio of ${ }^{13} \mathrm{C} /{ }^{12} \mathrm{C}$ of the leaf samples and $R_{\text {standard }}$ is the ratio of ${ }^{13} \mathrm{C} /{ }^{12} \mathrm{C}$ of standard materials. As tested, the precision of the $\delta^{13} \mathrm{C}$ was $0.1 \%$ against a standard with known isotopic composition.

\subsection{Statistical analysis}

Simple linear regression analyses (SPSS 11.5) were performed to examine the relationships of DG (depth of groundwater table) with three measured parameters (i.e. SD, SLA and $\delta^{13} \mathrm{C}$ ) of Populus euphratica Oliv. trees. The equations of the best-fitting curve estimation between DG and the three parameters were obtained by Curve Expert software (version 1.4).

\section{Results}

\subsection{Summary of measurements in sampling plots}

The investigation results of 42 plots were shown in Table 1. According to analysis we have found that the optimal relationship between DG and PD can be expressed by the hoerl model, as follows:

$$
P D=4.557 \times 10^{-4} \times 0.989^{D G} \times D G^{2.92}, R^{2}=0.87 .
$$

That is, $P D$ increases with the increase of DG, reaches its maximum when $\mathrm{DG}=2.7 \mathrm{~m}$, and then decreases gradually. The optimal relationship between DG and RBF can be expressed by the $3^{\text {rd }}$ degree polynomial model. It presents as:

$$
\begin{aligned}
R B F= & -5.98+0.45 D G-8.24 \times 10^{-4} D G^{2}+ \\
& 5.66 \times 10^{-7} D G^{3}, R^{2}=0.76 .
\end{aligned}
$$

$\mathrm{RBF}$ increases clearly with the increase of DG.

\subsection{Variation of stomatal density}

The stomatal density (SD) of Populus euphratica Oliv. trees from the 42 sampling plots ranges from 105 to 218 pore $/ \mathrm{mm}^{2}$ with a mean value of 158.4 pore $/ \mathrm{mm}^{2}$, and the relationship between SD and DG is not linear as shown in Fig. 5. Specifically, SD decreases drasticcally with increasing DG, reaching its first minimum at a depth of $2.7 \mathrm{~m}\left(105\right.$ pore $\left./ \mathrm{mm}^{2}\right)$, and then bounces back to a high level at $3.7 \mathrm{~m}$ of DG $\left(210\right.$ pore $\left./ \mathrm{mm}^{2}\right)$. After a relatively stable plateau of SD (195-210 pore $/ \mathrm{mm}^{2}$ ) at the depths ranging $3.7-5.2 \mathrm{~m}$, SD decreases again with increasing DG, reaching its second minimum at a depth of $8.5 \mathrm{~m}$. It should be particularly noted that Populus euphratica Oliv. forest is not the dominant component of riparian ecosystem any longer where the groundwater table is too shallow. The riparian vegetation including Populus euphratica Oliv. forest gives away to desert vegetation where the groundwater table becomes rather deep. 
Table 1 Population density (PD), height, diameter at breast (DBH), ratio of died branches to full branches (RBF) and the depth of groundwater table (DG) in the 42 sampling plots

\begin{tabular}{|c|c|c|c|c|c|c|c|c|c|}
\hline \multirow{2}{*}{ No. } & \multirow{2}{*}{$\mathrm{DG}(\mathrm{cm})$} & \multirow{2}{*}{ PD $\left(\right.$ Tree $\left./ \mathrm{hm}^{2}\right)$} & \multicolumn{3}{|c|}{ Height (m) } & \multicolumn{3}{|c|}{$\mathrm{DBH}(\mathrm{cm})$} & \multirow{2}{*}{ RBF (\%) } \\
\hline & & & Max. & Mean & Min. & Max. & Mean & Min. & \\
\hline 1 & 548 & 47.78 & 11.3 & 8.4 & 6.6 & 210 & 158 & 142 & 36.99 \\
\hline 2 & 345 & 477.60 & 8.4 & 6.5 & 3.2 & 157 & 149 & 133 & 21.22 \\
\hline 3 & 205 & 103.50 & 13.6 & 10.7 & 8.5 & 205 & 135 & 107 & 3.27 \\
\hline 4 & 290 & 668.80 & 8.5 & 6.3 & 5.4 & 60 & 53 & 40 & 15.53 \\
\hline 5 & 231 & 135.30 & 12.0 & 9.1 & 6.4 & 174 & 131 & 109 & 10.01 \\
\hline 6 & 283 & 63.69 & 20.6 & 10.7 & 9.2 & 298 & 233 & 166 & 11.06 \\
\hline 7 & 300 & 350.00 & 9.5 & 6.6 & 4.3 & 254 & 208 & 186 & 19.75 \\
\hline 8 & 315 & 246.80 & 9.9 & 8.4 & 5.3 & 242 & 211 & 131 & 18.45 \\
\hline 9 & 217 & 111.40 & 16.7 & 12.5 & 8.0 & 270 & 174 & 123 & 7.50 \\
\hline 10 & 359 & 103.50 & 17.6 & 12.4 & 8.1 & 266 & 196 & 159 & 21.74 \\
\hline 11 & 522 & 39.80 & 17.3 & 15.6 & 10.0 & 301 & 256 & 210 & 31.93 \\
\hline 12 & 331 & 326.40 & 21.0 & 16.5 & 13.0 & 296 & 240 & 207 & 18.03 \\
\hline 13 & 603 & 21.05 & 10.5 & 8.0 & 7.6 & 110 & 97 & 80 & 46.27 \\
\hline 14 & 220 & 198.20 & 11.9 & 9.3 & 8.4 & 180 & 158 & 96 & 9.64 \\
\hline 15 & 208 & 111.40 & 8.8 & 7.9 & 5.5 & 203 & 184 & 133 & 3.87 \\
\hline 16 & 415 & 71.64 & 9.1 & 6.4 & 3.7 & 202 & 152 & 113 & 27.72 \\
\hline 17 & 846 & 7.96 & 15.1 & 15.1 & 15.0 & 360 & 360 & 360 & 81.04 \\
\hline 18 & 503 & 31.84 & 17.3 & 14.4 & 9.7 & 297 & 233 & 113 & 41.72 \\
\hline 19 & 270 & 95.54 & 13.3 & 10.8 & 6.7 & 243 & 165 & 157 & 9.79 \\
\hline 20 & 423 & 15.92 & 10.2 & 10.0 & 9.8 & 156 & 144 & 132 & 24.95 \\
\hline 21 & 766 & 15.92 & 15.0 & 13.2 & 11.0 & 310 & 280 & 250 & 54.99 \\
\hline 22 & 743 & 47.78 & 14.7 & 12.8 & 11.0 & 230 & 169 & 144 & 54.29 \\
\hline 23 & 780 & 7.96 & 9.5 & 9.5 & 9.5 & 140 & 140 & 140 & 62.00 \\
\hline 24 & 751 & 55.72 & 23.0 & 14.1 & 11.0 & 310 & 272 & 246 & 59.25 \\
\hline 25 & 777 & 7.96 & 20.1 & 20.1 & 20.0 & 427 & 427 & 427 & 63.95 \\
\hline 26 & 805 & 7.96 & 18.2 & 18.2 & 18.0 & 268 & 268 & 268 & 68.03 \\
\hline 27 & 468 & 127.40 & 12.1 & 9.0 & 7.9 & 166 & 148 & 121 & 31.33 \\
\hline 28 & 198 & 828.00 & 8.1 & 6.4 & 5.3 & 55 & 43 & 29 & 2.45 \\
\hline 29 & 378 & 222.90 & 11.3 & 8.7 & 5.6 & 178 & 154 & 132 & 23.98 \\
\hline 30 & 434 & 63.69 & 19.5 & 16.5 & 15.0 & 210 & 193 & 177 & 31.09 \\
\hline 31 & 201 & 191.00 & 11.0 & 7.4 & 4.6 & 90 & 68 & 57 & 3.41 \\
\hline 32 & 366 & 183.10 & 8.8 & 6.5 & 4.4 & 198 & 122 & 10 & 21.13 \\
\hline 33 & 339 & 63.69 & 12.6 & 9.1 & 4.5 & 126 & 81 & 65 & 19.86 \\
\hline 34 & 280 & 80.00 & 11.9 & 8.3 & 6.1 & 253 & 162 & 126 & 10.53 \\
\hline 35 & 710 & 55.73 & 23.0 & 18.5 & 13.0 & 295 & 217 & 187 & 43.33 \\
\hline 36 & 327 & 262.70 & 14.4 & 10.4 & 5.1 & 223 & 188 & 145 & 18.87 \\
\hline 37 & 347 & 660.70 & 11.7 & 9.3 & 7.6 & 289 & 214 & 144 & 21.49 \\
\hline 38 & 402 & 143.30 & 13.0 & 8.0 & 6.4 & 130 & 119 & 87 & 21.84 \\
\hline 39 & 211 & 72.37 & 13.8 & 10.3 & 8.4 & 308 & 144 & 119 & 4.85 \\
\hline 40 & 394 & 199.00 & 12.0 & 11.3 & 9.5 & 233 & 215 & 188 & 21.84 \\
\hline 41 & 457 & 175.10 & 27.0 & 18.0 & 16.0 & 440 & 338 & 301 & 33.00 \\
\hline 42 & 725 & 15.92 & 21.0 & 15.6 & 10.0 & 236 & 221 & 206 & 31.09 \\
\hline
\end{tabular}




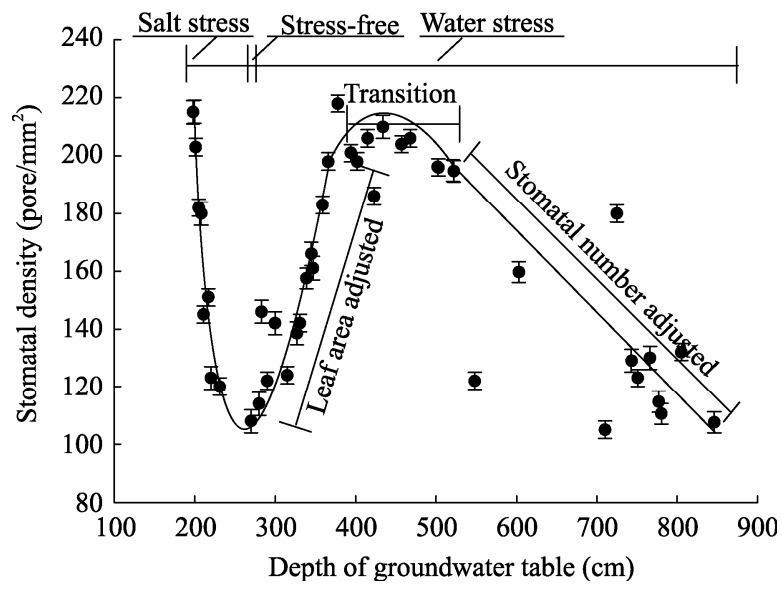

Fig. 5 Variations of stomatal density (SD) with the depth of groundwater table (DG)

\subsection{Variation of specific leaf area}

The specific leaf area (SLA) value of Populus euphratica Oliv. trees from the 42 sampling plots ranges from $5.35 \pm 0.15$ to $11.84 \pm 0.29 \mathrm{~m}^{2} / \mathrm{kg}$. SLA decreases exponentially with increasing DG as shown in Fig. 6. The exponential curve suggests SLA is more sensitive to DG when groundwater table is shallow and $3 \mathrm{~m}$ of DG seems to be a threshold beyond which SLA becomes less sensitive to DG.

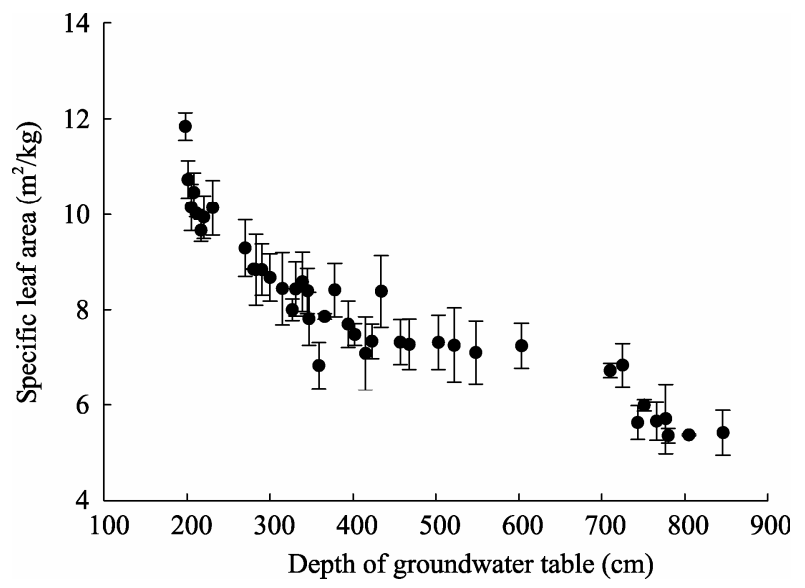

Fig. 6 Variations of specific leaf area (SLA) with the depth of groundwater table (DG)

\subsection{Changes of foliar $\delta^{13} \mathrm{C}$}

The $\delta^{13} \mathrm{C}$ value of Populus euphratica Oliv. leaves from the 42 sampling plots ranges from $-(25.5 \pm$ $0.43) \%$ to $-(30.21 \pm 0.63) \%$. Like SLA, the $\delta^{13} \mathrm{C}$ is also strongly dependent on DG as shown in Fig. 7. The trend curve in Fig. 7 suggests that the $\delta^{13} \mathrm{C}$ becomes more sensitive when the groundwater table is deep and $7 \mathrm{~m}$ of DG seems to be a threshold beyond which the $\delta^{13} \mathrm{C}$ signature becomes more sensitive to DG.

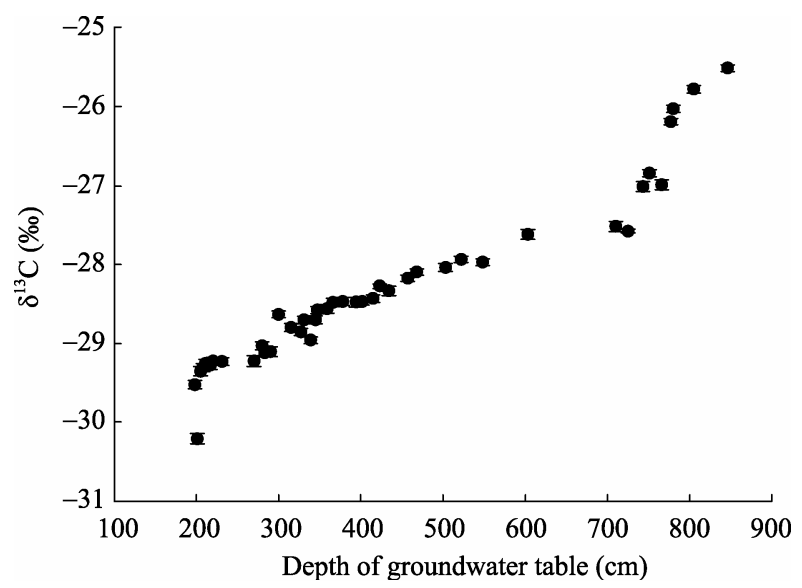

Fig. 7 Variations of stable carbon isotopic composition $\left(\delta^{13} \mathrm{C}\right)$ with the depth of groundwater table (DG)

\subsection{Interrelationships among SD, SLA and $\delta^{13} \mathrm{C}$}

The paired relationships among the three analyzed parameters (i.e. leaf SD, SLA, and foliar $\delta^{13} \mathrm{C}$ ) were examined and no relationships of SD with SLA and $\delta^{13} \mathrm{C}$ were found. But, a strongly negative correlation between SLA and $\delta^{13} \mathrm{C}$ values is unequivocally expressed as shown in Fig. 8 with $R^{2}$ being as high as $0.82(n=42, P<0.01)$.

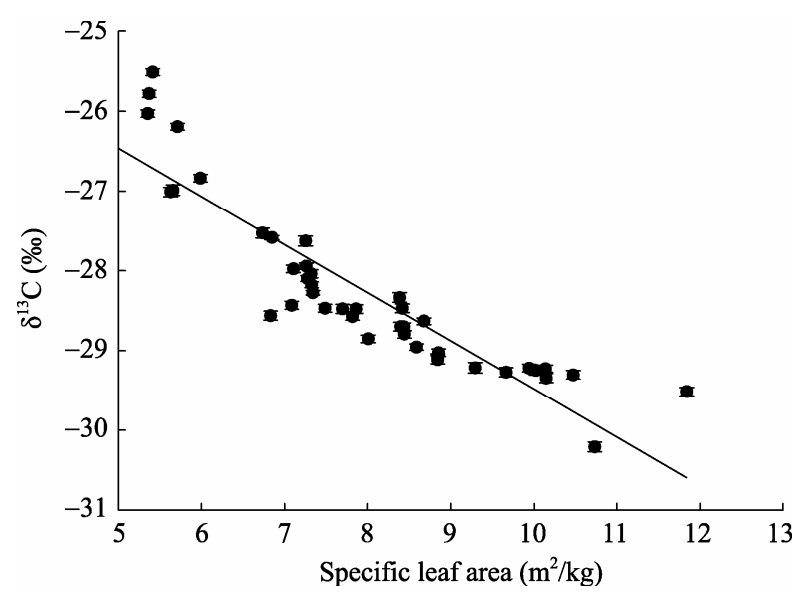

Fig. 8 Relationship between specific leaf area (SLA) and $\delta^{13} \mathrm{C}$ values

\section{Discussion}

\subsection{Variation of leaf stomatal density}

The leaf stoma, a pivotal gate controlling the exchange 
of $\mathrm{CO}_{2}$ and water vapour, plays a major role in the response of plants to environmental stress (Xu and Zhou, 2008). The relationship between stomatal density and water stress has been paid much attention. Several reports have shown a linear decreasing trend of leaf stomatal density (SD) of Alhagi sparsifolia, Phaseolus vulgaris, Phragmites communis, and Populus euphratica Oliv. with increasing water stress (Zhang et al., 2004; Martínez et al., 2007). While other reports showed an opposite trend of Leymus chinensis and Vicia faba (Spence et al., 1986; Chaves et al., 2003; Yang et al., 2007). Relevant to this study is a bell-shaped relationship between SD and water stress reported by several researchers (Liu et al., 2006; $\mathrm{Xu}$ and Zhou, 2008). Our results show that stomatal density has a bell-shaped relationship between leaf SD and water stress for the depths of groundwater table ranging 2.7-8.5 $\mathrm{m}$ (Fig. 5). That is, leaf SD first increased and then decreased with increasing water stress. Liu et al. (2006) reported that stomatal densities of leaves from several varieties of Jujube also have similar patterns under a drought gradient. The increasing trend of leaf SD with increasing water stress was proven to have resulted from the reduction of leaf area to reduce transpiration with stomatal number remaining as a constant (Chaves et al., 2003; Gazanchian et al., 2007). The decreasing trend of leaf SD with continuously increasing water stress after the leaf SD peak was proven to have been caused by the reduction of stomatal number and was in turn caused by the inefficiency in cell division and stomatal development (Aguirrezabal et al., 2006; Xu and Zhou, 2008). The peak or plateau is a transitional or self-adapting area from leaf-area reduction to stomatal-number reduction.

As mentioned earlier, this study did document a bell-shaped relationship between leaf SD and water stress for the depths of groundwater table ranging 2.7-8.5 m. But, a steep leaf SD declining trend for the depths of groundwater table between 2.0 and $2.7 \mathrm{~m}$ is our new finding (see Fig. 5). That is, this study appears to be the first to report a bi-mode relationship between leaf SD and water stress, and here water stress refers to the depth of groundwater table (DG). The bi-mode relationship exhibits two leaf SD minimums (one at $2.7 \mathrm{~m}$ and another at $8.5 \mathrm{~m}$ of DG) and two leaf SD maximums (one at $2.0 \mathrm{~m}$ and another at $3.7 \mathrm{~m}$ of DG). We think that the bell-shaped section of the leaf SD variation curve between 2.7 and $8.5 \mathrm{~m}$ of DG can be explained by the same rationale for explaining the bell-shaped relationships proposed by several researchers (Liu et al., 2006; Xu and Zhou, 2008). But, the difficulty lies in explaining the declining trend of leaf SD with increasing DG within the shallow portion of groundwater tables (between 2.0 and $2.7 \mathrm{~m}$ ). The drastic decreasing trend within the shallow portion of groundwater table suggests that the leaf SD variations are independent of water stress and that other ecological factors may take over the responsibility. Here, the first suspect we have is salt that was effectively accumulated around the water table depth under a shallow groundwater-table condition through soil-water evaporation and also through soil capillary actions, as evidenced in the work from Tarim Basin (Zheng et al., 2005).

To sum up, salt stress appears in shallow groundwater conditions (less than $2.7 \mathrm{~m}$ ) and water stress happens in deep groundwater conditions (larger than $2.7 \mathrm{~m}$ ), the thin layer around $2.7 \mathrm{~m}$ probably being a stress-free zone (neither salt stress nor water stress). Leaf SD fluctuated according to the DG variation, first it decreased with increasing DG, then increased at DG ranging $2.7-3.7 \mathrm{~m}$, and after a relatively stable plateau of SD at DG ranging 3.7-5.2 m, decreased again with increasing DG (Fig. 5). It should be indicated that the $5.2 \mathrm{~m}$ threshold of DG is approximately in agreement with the lower limit of water-stress threshold reported by Chen et al. (2003) and the $8.5 \mathrm{~m}$ threshold of DG is approximately in agreement with the upper limit of water stress threshold reported by Zhang et al. (2004).

\subsection{Variation of specific leaf area}

Specific leaf area (SLA, $\mathrm{m}^{2} / \mathrm{kg}$ ), the ratio of fresh leaf area to leaf dry mass, influences leaf physiology, photosynthesis, and whole plant carbon gain. Therefore, it becomes an important ecophysiological parameter, widely used in ecosystem process-based models (Landsberg and Waring, 1997; Sands and Landsberg, 2002; Battaglia et al., 2004; Corbeels et al., 2005) or canopy gas-exchange models (Davi et al., 2008). However, it also is affected by environmental conditions such as soil water status, light, and nitrogen sup- 
ply (Li et al., 2000; Roderick et al., 2000; Whitehead and Beadle, 2004; White and Scott, 2006; Pinkard et al., 2007), and thus used as an indicator of leaf structure to environmental stress. The relationship between variations in SLA and water availability has been much reported. Specific leaf area exhibits considerable phenotypic plasticity with water gradients, and commonly decreases with decreasing soil water availability (Pierce et al., 1994; Medhurst et al., 1999; Roderick et al., 2000; Turner et al., 2008). The same results were also observed in our study area: the specific leaf area (SLA) value of Populus euphratica Oliv. showed its large plasticity ranging from 5.35 to $11.84 \mathrm{~m}^{2} / \mathrm{kg}$; SLA decreases exponentially with increasing DG (Fig. 6). The decreasing trend of the leaf area was a result of the physiological response of Populus euphratica Oliv. trees to increasing water stress (i.e. increasing DG) to reduce transpiration. It has been reported that SLA is determined by both leaf density and thickness, meaning that SLA is inversely proportional to them. The canopies of Populus euphratica Oliv. forests are generally open to allow for uniform light distribution within the canopies, which can result in less effect of leaf density on SLA. But the increases of the internal tissue density of leaves, being the feature of xerophytic structure, can cause SLA to decrease.

\subsection{Changes of foliar $\delta^{13} \mathrm{C}$}

Plant foliar $\delta^{13} \mathrm{C}$ is mainly controlled by photosynthesis and is also influenced by many environmental factors (Farquhar et al., 1989; Liu et al., 2004). Water condition is regarded as an important factor affecting $\delta^{13} \mathrm{C}$ values in arid regions (Chen et al., 2002; Ma et al., 2007). It has been reported that the foliar $\delta^{13} \mathrm{C}$ values of $\mathrm{C}_{3}$ desert plants range from $-21 \%$ to $-29 \%$ in the desert areas (Rundel et al., 1999). Our results showed that the $\delta^{13} \mathrm{C}$ values of Populus euphratica Oliv are between $-(25.51 \pm 0.43) \%$ and $-(30.21 \pm 0.63) \%$. The relationships between plant $\delta^{13} \mathrm{C}$ signature and soil moisture or water accessibility in arid area were recently reported. For example, Ma et al. (2007) reported a strong negative correlation between Reaumuria soongorica foliar $\delta^{13} \mathrm{C}$ and soil water content based on plant samples obtained from northwestern China. They found that the main factor affecting $\delta^{13} \mathrm{C}$ values in the desert was soil water con- tent (SWC). Chen et al. (2002) reported a robust negative correlation between Leymus chinensis foliar $\delta^{13} \mathrm{C}$ signature and soil water content in Xilin River Basin of Inner Mongolia. Our results show that $\delta^{13} \mathrm{C}$ values increase with the increase of DG (Fig. 7). In our study area, the mean annual precipitation is only $41 \mathrm{~mm}$. Soil water content (SWC) is mainly contributed by groundwater through capillary action. The deeper DG is, the weaker the capillary action is. In other words, SWC decreases with the increase of DG. Therefore, we concluded that $\delta^{13} \mathrm{C}$ values are significantly and negatively correlated with SWC, which corresponds to the above results. In order to adapt themselves to arid environments, plants take many adaptive strategies such as reducing water evaporation and closing stoma partly, as a result $\delta^{13} \mathrm{C}$ values increased. Furthermore, a number of experiments conducted in other areas concluded that stomatal conductance and photosynthetic discrimination under water-stressed conditions are normally enriching ${ }^{13} \mathrm{C}$ signals in $\mathrm{C}_{3}$ plant species (Bowling et al., 2002; Lee et al., 2005; Feng et al., 2008). Our study shows that foliar $\delta^{13} \mathrm{C}$ values of Populus euphratica Oliv. trees increase with increasing water stress (i.e. increasing DG), being in a good agreement with the results from the Mongolian Plateau (Lee et al., 2005; Feng et al., 2008) and other areas (Bowling et al., 2002).

As mentioned earlier, SLA is inversely proportional to both leaf density and thickness. The decreasing trend of SLA is mainly due to the increase of the internal tissue density of leaves (i.e. thickness) with increasing water stress, and increase of leaf thickness can influence stomatal conductance and photosynthetic discrimination, which causes the increase of $\delta^{13} \mathrm{C}$ values. In other words, $\delta^{13} \mathrm{C}$ values decrease with the increase of SLA (Fig. 8).

\section{Conclusions}

Groundwater is a crucial ecological factor to affect physiological traits on Populus euphratica Oliv. and, in turn, influence the growth status of the species in the study area. There is a bi-mode relationship between SD and water stress. Salt stress appears in shallow groundwater conditions (less than $2.7 \mathrm{~m}$ ) and water stress happens in deep groundwater conditions 
(larger than $2.7 \mathrm{~m}$ ), the thin layer around $2.7 \mathrm{~m}$ probably being a stress-free zone (neither salt stress nor water stress). SLA decreases exponentially with increasing DG. The bigger foliar $\delta^{13} \mathrm{C}$ values of Populus euphratica Oliv. trees are, the more seriously the species suffers from water stress. Populus euphratica Oliv. has a low productivity due to water stress. Therefore, the niche of the species must be paid more attention

\section{References}

Aguirrezabal L, Bouchier-Combaud S, Radziejwoski A, et al. 2006. Plasticity to soil water deficit in Arabidopsis thaliana: dissection of leaf development into underlying growth dynamic and cellular variables reveals invisible phenotypes. Plant, Cell and Environment, 29(12): 2216-2227.

Anyia A O, Herzog H. 2004. Water-use efficiency, leaf area and leaf gas exchange of cowpeas under mid-season drought. European Journal of Agronomy, 20(4): 327-339.

Battaglia M, Sands P, White D, et al. 2004. CABALA: a linked carbon, water and nitrogen model of forest growth for silvicultural decision support. Forest Ecology and Management, 193(1): 251-282.

Bowling D R, McDowell N G, Bond J R, et al. 2002. $\delta^{13} \mathrm{C}$ content of ecosystem respiration is linked to precipitation and vapor pressure deficit. Oecologia, 131(1): 113-124.

Ceulemans R, Van Praet L, Jiang X N. 1995. Effects of $\mathrm{CO}_{2}$ enrichment, leaf position and clone on stomatal index and epidermal cell density in poplar (Populus). New Phytologist, 131(1): 99-107.

Chaves M M, Maroco J P, Pereira J S. 2003. Understanding plant responses to drought from genes to the whole plant. Functional Plant Biology, 30(3): 239-264.

Chen S P, Bai Y F, Han X G. 2002. Variation of water-use efficiency of Leymus chinensis and Cleistogenes squarrosa in different plant communities in Xilin River Basin, Inner Mongolia. Acta Botanica Sinica, 44(12): 1484-1490.

Chen Y N, Chen Y P, Li W H, et al. 2003. Proline accumulation responses of Populus euphratica to groundwater table variations in Tarim River. Chinese Science Bulletin, 48(9): 958-961.

Corbeels M, McMurtrie R E, Pepper D A, et al. 2005. Long-term changes in productivity of eucalypt plantations under different harvest residue and nitrogen management practices: a modeling analysis. Forest Ecology and Management, 217(1): 1-18.

Davi H, Barbaroux C, Dufrêne E, et al. 2008. Modelling leaf mass per area in forest canopy as affected by prevailing radiation conditions. Ecological Modelling, 211(3): 339-349.

Elias P. 1995. Stomatal density and size of apple tree growing under irrigated and non-irrigated conditions. Biologia, 50(1): 115-118.

Farquhar G D, Ehleringer J R, Hubick K T. 1989. Carbon isotope discrimination and photosynthesis. Annual Review of Plant Biology, 40(1): 503-537.

Feng Z D, Wang L X, Ji Y H, et al. 2008. Climatic dependency of soil for protecting Populus euphratica Oliv. from extinction in the study area.

\section{Acknowledgements}

The work was financially supported by the National Natural Science Foundation of China $(91025015,30770387)$. The authors are grateful for the technical assistance from Professor JianQuan LIU.

organic carbon isotopic composition along the $\mathrm{S}-\mathrm{N}$ transect from $34^{\circ} \mathrm{N}$ to $52^{\circ} \mathrm{N}$ in central-east Asia. Palaeogeography, Palaeoclimatology, Palaeoecology, 257(3): 335-343.

Gazanchian A, Hajheidari M, Sima N K, et al. 2007. Proteome response of Elymus elongatum to severe water stress and recovery. Journal of Experimental Botany, 58(2): 291-300.

Ji X B, Kang E S, Chen R S, et al. 2006. Analysis of water resources supply and demand and security of water resources development in irrigation regions of the middle reaches of the Heihe River Basin, Northwest China. Agricultural Sciences in China, 5(2): 130-140.

Kitajima K, Poorter L. 2010. Tissue-level leaf toughness, but not lamina thickness, predicts sapling leaf lifespan and shade tolerance of tropical tree species. New Phytologist, 186(3): 708-721.

Klich M G. 2000. Leaf variations in Elaeagnus angustifolia related to environmental heterogeneity. Environmental and Experimental Botany, 44(3): 171-183.

Landsberg J J, Waring R H. 1997. A generalised model of forest productivity using simplified concepts of radiation-use efficiency, carbon balance and partitioning. Forest Ecology and Management, 95(3): 209-228.

Lee X W, Feng Z D, Guo L L, et al. 2005. Soil and plant- $\delta^{13} \mathrm{C}$ variations along a N-S $\left(32-55^{\circ} \mathrm{N}\right)$ transect in east central Asia. Global Biogeochemical Cycles, 19(3): 1-8.

Li C, Berninger F, Koskela J, et al. 2000. Drought responses of Eucalyptus microtheca provenances depend on seasonality of rainfall in their place of origin. Australian Journal of Plant Physiology, 27(3): 231-238.

Li Q, Feng Q, Zhai L. 2010. Study of the height growth dynamic based on tree-ring data in Populus euphratica from the lower reach of the Heihe River, China. Dendrochronologia, 28(1): 49-64.

Liu F, Stüzel H. 2004. Biomass partitioning, specific leaf area, and water use efficiency of vegetable amaranth (Amaranthus spp.) in response to drought stress. Scientia Horticulturae, 102(1): 15-27.

Liu S P, Liu J M, Cao J Y, et al. 2006. Stomatal distribution and character analysis of leaf epidermis of Jujube under drought stress. Journal of Anhui Agricultural Sciences, 34(7): 1315-1318.

Liu Y, Ma L, Leavitt S W, et al. 2004. A preliminary seasonal precipitation reconstruction from tree-ring stable carbon isotopes at $\mathrm{Mt}$. Helan, China, since AD 1804. Global and Planetary Change, 41(3): 229-239. 
Ma H C, Fung L, Wang S S, et al. 1997. Photosynthetic response of Populus euphratica to salt stress. Forest Ecology and Management, 93(1): 55-61.

Ma J Y, Chen K, Xia D S, et al. 2007. Variation in foliar stable carbon isotope among populations of a desert plant, Reaumuria soongorica (Pall.) Maxim. in different environments. Journal of Arid Environments, 69(3): 365-374.

Marcelis L F M, Heuvelink E, Goudriaan J. 1997. Modelling of biomass production and yield of horticultural crops: a review. Scientia Horticulturae, 74(1): 83-112.

Martínez J P, Silva H, Ledent J F, et al. 2007. Effect of drought stress on the osmotic adjustment, cell wall elasticity and cell volume of six cultivars of common beans (Phaseolus vulgaris L.). European Journal of Agronomy, 26(1): 30-38.

Medhurst J L, Battaglia M, Cherry M L, et al. 1999. Allometric relationships for Eucalyptus nitens (Deane and Maiden) Maiden plantations. Trees-Structure and Function, 14(2): 91-101.

Naiman R J, Décamps H. 1997. The ecology of interfaces: riparian zones. Annual Review of Ecology and Systematics, 28: 621-658.

Nautiyal P C, Rachaputi N R, Joshi Y C. 2002. Moisture-deficit-induced changes in leaf-water content, leaf carbon exchange rate and biomass production in groundnut cultivars differing in specific leaf area. Field Crops Research, 74(1): 67-79.

Nilsson C, Jansson R, Zinko U. 1997. Long-term responses of river-margin vegetation to water-level regulation. Science, 276 : 798-800.

Pierce L L, Running S W, Walker J. 1994. Regional scale relationships of leaf area index to specific leaf area and leaf nitrogen content. Ecological Applications, 4(2): 313-321.

Pinkard E A, Battaglia M, Mohammed C L. 2007. Defoliation and nitrogen effects on photosynthesis and growth of Eucalyptus globulus. Tree physiology, 27(7): 1053-1063.

Retuerto R, Woodward F I. 1993. The influences of increased $\mathrm{CO}_{2}$ and water supply on growth, biomass allocation and water use efficiency of Sinapisalba L. grown under different wind speeds. Oecologia, 94(3): 415-427.

Roderick M L, Berry S L, Noble I R. 2000. A framework for understanding the relationship between environment and vegetation based on the surface area to volume ratio of leaves. Functional Ecology, 14(4): 423-437.

Royer D L. 2001. Stomatal density and stomatal index as indicators of paleoatmospheric $\mathrm{CO}_{2}$ concentration. Review of Palaeobotany and Palynology, 114(1): 1-28.

Sands P J, Landsberg J J. 2002. Parameterisation of 3-PG for plantation grown Eucalyptus globulus. Forest Ecology and Management, 163(1): 273-292.

Säumel I, Ziche D, Yu R, et al. 2011. Grazing as a driver for Populus euphratica woodland degradation in the semi-arid Aibi River region, northwestern China. Journal of Arid Environments, 75(3): 265-269.

Sidle W C. 2004. Predicting sustainable ground water to constructed riparian wetlands: shaker trace, Ohio, USA. The Environmentalist, 24(3): 179-186.
Spence R D, Wu H, Sharpe P J H. et al. 1986. Water stress effects on guard cell anatomy and the mechanical advantage of the epidermal cells. Plant, Cell and Environment, 9(3): 197-202.

Tardieu F, Granier C, Muller B. 1999. Modelling leaf expansion in a fluctuating environment: are changes in specific leaf area a consequence of changes in expansion rate? New Phytologist, 143(1): 33-43.

Tichá I. 1982. Photosynthetic characteristics during ontogenesis of leaves. 7. Stomata density and sizes. Photosynthetica, 16(2): $375-471$.

Turner N C, Schulze E D, Nicolle D, et al. 2008. Annual rainfall does not directly determine the carbon isotope ratio of leaves of Eucalyptus species. Physiologia Plantarum, 132(4): 440-445.

Vitousek P M, Field C B, Matson P A. 1990. Variation in foliar $\delta^{13} \mathrm{C}$ in Hawaiian Metrosideros polymorpha: a case of internal resistance? Oecologia, 84(3): 362-370.

Wang Y, Chen X, Xiang C B. 2007. Stomatal density and bio-water saving. Journal of Integrative Plant Biology, 49(10): 1435-1444.

Whitehead D, Beadle C L. 2004. Physiological regulation of productivity and water use in Eucalyptus: a review. Forest Ecology and Management, 193(1-2): 113-140.

White J D, Scott N A. 2006. Specific leaf area and nitrogen distribution in New Zealand forest species independently respond to intercepted light. Forest Ecology and Management, 226(1-3): 319-329.

Williams D G, Ehleringer J R. 1996. Carbon isotope discrimination in three semi-arid woodland species along a monsoon gradient. Oecologia, 106(4): 455-460.

Xu Z, Zhou G. 2008. Responses of leaf stomatal density to water status and its relationship with photosynthesis in a grass. Journal of Experimental Botany, 59(12): 3317-3325.

Yadollahi A, Arzani K, Ebadi A, et al. 2011. The response of different almond genotypes to moderate and severe water stress in order to screen for drought tolerance. Scientia Horticulturae, 129(3): 403-413.

Yang H M, Wang G X. 2001. Leaf stomatal densities and distribution in Triticum aestivum under drought and $\mathrm{CO}_{2}$ enrichment. Acta Phytoecologica Sinica, 25(3): 312-316.

Yang L M, Han M, Zhou G S, et al. 2007. The changes in water-use efficiency and stoma density of Leymus chinensis along Northeast China transect. Acta Ecologica Sinica, 27(1): 16-23.

Zhang L, Dong Z C, Huang X L. 2004. Modeling on relation between major plants growth and groundwater depth in arid area. Journal of Desert Research, 24(1): 110-113.

Zhang W W, Shi S S. 2002. Study on the relation between groundwater dynamics and vegetation degeneration in Erjina Oasis. Journal of Glaciology and Geocryology, 24(4): 421-425.

Zheng D, Li W H, Chen Y P, et al. 2005. Relations between groundwater and natural vegetation in the arid zone. Resources Science, 27(4): 160-167.

Zheng S X, Shangguan Z P. 2007. Foliar $\delta^{13} \mathrm{C}$ values of nine dominant species in the Loess Plateau of China. Photosynthetica, 45(1): $110-119$. 